Pesq. Vet. Bras. 35(8):749-761, agosto 2015 DOI: $10.1590 / \mathrm{S} 0100-736 \mathrm{X} 2015000800007$

\title{
Bases ósseas e musculares dos cortes comerciais do tronco de jacaré-do-Pantanal (Caiman yacare Daudin, 1802) ${ }^{1}$
}

\author{
Sandra I.S. Figueiredo ${ }^{2 *}$, Luciana B.M. Araújo ${ }^{3}$, Rosa H.S. Ferraz ${ }^{2}$, Flávio R. Guimarães ${ }^{2}$, \\ Jéssica L. Cantarini ${ }^{4}$ e Eugênio G. Araújo ${ }^{3}$
}

\begin{abstract}
Figueiredo S.I.S., Araújo L.B.M., Ferraz R.H.S., Guimarães F.R., Cantarini J.L. \& Araújo E.G. 2015. [Bone and muscular bases of commercial cuts from yacare caiman (Caiman yacare Daudin, 1802.] Bases ósseas e musculares dos cortes comerciais do tronco de jacaré-do-Pantanal (Caiman yacare Daudin, 1802). Pesquisa Veterinária Brasileira 35(8):749-761. Departamento de Ciências Básicas e Produção Animal, Faculdade de Agronomia, Medicina Veterinária e Zootecnia, Universidade Federal de Mato Grosso, Avenida Fernando Corrêa da Costa 2367, Cidade Universitária, Cuiabá, MT 78060-900, Brazil. E-mail: sandrafigueiredo@ufmt.br

Yacare Caiman meat consumption has become a marketing trend and a commodity on the rise in Mato Grosso state in Brazil. In the last four years, cuts from the trunk represented $28.40 \%$ of total meat sales. Although evolutionary studies, morphophysiological ontogenetic and technology research have been carried out, characterization of muscle and bone bases of cuts from the torso has not been previously reported. The aim of this research is to describe the muscles and corresponding bones related to sirloin, filet mignon and meat trims cuts. To describe the bones, we used six boned carcasses from juvenile Yacare Caiman, as well as an adult specimen, obtained by donation after death from the Federal University of Mato Grosso Zoo. The bones were macerated, bleached and their anatomical details recorded. In order to study the muscle, 24 juvenile specimens were obtained after slaughter and skinning and dissected on both sides. The sirloin cut consists of the semispinal, longissimus and iliocostalis muscles, which are inserted on thoracic vertebrae and ribs, as well as lumbar and sacral ribs. The meat trims cut is formed by latissimus dorsi, serratus, pectoral and abdominal (external oblique, internal oblique, transversus and rectus) muscles, based in various bones: bone ribs are the thoracic, lumbar, and sacral ribs, the gastralia, the sternum and epipúbis. The filet mignon cut is formed by the internal puboischiofemoralis cranial (sublumbar) muscle and by the troncocaudal (ventral surface of the pelvis) muscle.
\end{abstract}

INDEX TERMS: Yacare caiman, Caiman yacare, Alligatoridae, anatomy, meat trims, meat, sirloin cut, filet mignon.

RESUMO.- 0 consumo de carne de jacaré-do-Pantanal tornou-se uma tendência de mercado e uma cadeia produtiva em ascensão no Estado de Mato Grosso, sendo 28,40\% da

\footnotetext{
${ }^{1}$ Recebido em 4 de julho de 2014.

Aceito para publicação em 8 de março de 2015.

${ }^{2}$ Departamento de Ciências Básicas e Produção Animal, Faculdade de Agronomia, Medicina Veterinária e Zootecnia, Universidade Federal de Mato Grosso (UFMT), Av. Fernando Corrêa da Costa 2367, Cidade Universitária, Cuiabá, MT 78060-900.*Autor para correspondência: sandrafigueiredo@ufmt.br

${ }^{3}$ Departamento de Medicina Veterinária, Escola de Veterinária e Zootecnia, Universidade Federal de Goiás (UFG), Campus Samambaia, Rodovia Goiânia-Nova Veneza, Cx. Postal 131, Goiânia, GO 74001-970, Brasil.

${ }^{4}$ Mestranda em Ciências Veterinárias, UFMT, Av. Fernando Corrêa da Costa 2367, Cidade Universitária, Cuiabá, MT 78060-900.
}

carne comercializada nos últimos quatro anos oriundos do tronco. Estudos evolutivos, morfofisiológicos, ontogenéticos e tecnológicos foram desenvolvidos, mas não há descrição da musculatura e bases ósseas dos cortes comerciais. Objetivou-se descrever os músculos e correspondentes bases ósseas dos cortes filé de lombo, filé mignon e aparas. Na descrição óssea, utilizaram-se seis carcaças desossadas de exemplares juvenis de jacaré-do-Pantanal, além de um exemplar adulto, obtido por doação após óbito, do Zoológico da UFMT. Os ossos foram macerados em água corrente, clareados e descritos. Para a descrição muscular, 24 exemplares juvenis foram abatidos e esfolados, conservados em freezer e descongelados quando utilizados, sem qualquer fixação. Após a evisceração, foram dissecados em ambos os 
antímeros. Os músculos semiespinhal, longuíssimo e iliocostal, fixados nas vértebras e costelas torácicas, lombares e sacrais, formam o filé de lombo. 0 corte aparas é constituído pelos músculos grande dorsal, serrátil, peitoral e abdominais (oblíquo externo, oblíquo interno, transverso e reto), cuja base óssea corresponde as costelas torácicas, lombares e sacrais, a gastrália, o esterno e o epipúbis. Por sua vez, o m. puboisquiofemoral interno cranial, localizado na região sublombar e o $\mathrm{m}$. troncocaudal, da superfície ventral da pelve, compreendem o filé mignon.

TERMOS DE INDEXAÇÃO: Jacaré-do-Pantanal, Caiman yacare, Alligatoridae, anatomia, aparas, carne, filé de lombo, filé mignon.

\section{INTRODUÇÃO}

Em Mato Grosso, a criação comercial de jacaré-do-Pantanal é uma atividade industrial em ascensão, com criatórios e uma unidade processadora que comercializou entre 2009 e 2012, aproximadamente $114 \mathrm{mil} \mathrm{kg}$ de carne (SFA/MT 2013). A carne do jacaré-do-Pantanal ganhou importância econômica, tornou-se objeto de pesquisas (Vicente Neto et al. 2010, Vieira et al. 2012) e, devido ao seu valor nutricional, apresenta tendência de aumento de demanda no mercado nacional e externo.

Cortes da região do tronco de jacaré-do-Pantanal representam $28,40 \%$ do total da carne comercializada em Mato Grosso, correspondendo a mais de $50 \%$ da carcaça. Essa região abriga três cortes comerciais: filé de lombo, aparas e filé mignon, cujas quantias comercializadas no Estado entre 2009 a 2012 foram respectivamente, aproximadamente 12 mil; 18 mil e 3 mil kg (SFA/MT 2013).

A separação da carcaça em cortes e a embalagem individual agregam valor ao produto, proporcionando melhor apresentação e confiabilidade (Girardi et al. 2008), o que despertou interesse para a caracterização da carne do Caiman yacare nas diferentes regiões corporais (Cossu et al. 2007, Rodrigues et al. 2007). Dessa forma, embora o tronco de crocodilianos tenha sido estudado em uma perspectiva filogenética (Organ 2006, Tsuihiji 2007, Schwarz-Wings 2009) e ontogenética (Lima et al. 2011, Vieira et al. 2011), ainda há carência de informações sobre a morfologia do sistema esquelético e muscular do jacaré-do-Pantanal, principalmente relacionados aos cortes comerciais utilizados na indústria. Isto posto, descreveu-se os músculos e suas correspondentes bases ósseas que constituem os cortes comerciais localizados no tronco de C. yacare (filé de lombo, filé mignon e aparas) para assim subsidiar sua padronização.

\section{MATERIAL E MÉTODOS}

O projeto foi cadastrado no Sistema de Autorização e Informação em Biodiversidade - SISBIO (23717-1) e aprovado pelo Comitê de Ética em Pesquisa Animal da Universidade Federal de Mato Grosso (23108.018396/10-7).

Para a descrição óssea, foi utilizado um espécime de Caiman yacare adulto, obtido por doação, após óbito, do Zoológico da UFMT, além de seis carcaças desossadas de juvenis. Para a caraterização dos músculos, utilizaram-se 24 espécimes juvenis. Os animais juvenis foram obtidos de criatório localizado no município de Cáceres (MT) e apresentavam, em média, dois anos e meio de idade, quatro quilos de massa corporal e de 35 a $40 \mathrm{~cm}$ de circunferência abdominal, sendo esse último o critério utilizado para definir o momento do abate.

Para o processamento ósseo, foi realizada a desarticulação e identificação dos ossos previamente ao processo de maceração em água corrente, clareamento em solução de água oxigenada a 10 volumes e secagem em temperatura ambiente e na sombra. As partes com tecido fibroso ou cartilaginoso foram fixadas em solução aquosa de formaldeído a $10 \%$, dissecadas e submetidas a técnica de glicerinação de Giacomini (Silva et al. 2008). Os ossos do animal adulto, após o processamento, foram sequenciados para a montagem do esqueleto.

Para a dissecção dos músculos, em ambos os antímeros, os animais obtidos no frigorífico foram mantidos congelados para posterior dissecção a fresco. Após a evisceração, realizou-se a dissecção dos músculos com o auxílio de lupa de pala e lupa circular de luz fria. Para a adequada utilização dos termos anatômicos estabeleceu-se a posição anatômica de C. yacare, o qual apresenta posição quadrupedal, com a cabeça, pescoço, tronco e cauda dispostos longitudinalmente e paralelos em relação ao solo. A cabeça voltada para o horizonte e os quatro membros e a cauda apoiados no solo. Priorizou-se nas descrições e discussões dos resultados, o uso da literatura disponível sobre crocodilianos, na ausência dela, foi também utilizada informações sobre anfíbios, outros répteis viventes e extintos e aves.

A ausência de padronização da terminologia anatômica para os répteis levou à adoção de uma combinação dos sistemas de termos anatômicos existentes, a Nomina Anatomica Veterinaria - NAV (ICVGAN 2012) e a Nomina Anatomica Avium - NAA (Baumel et al. 1993). Quando os termos constantes nas nominas não puderam ser aplicados, em virtude das características da espécie, utilizou-se a nomenclatura mais recente encontrada na literatura, ou ainda, questionou-se a nomenclatura tradicionalmente utilizada e nominou-se estruturas, procurando adequar os nomes aos princípios de utilização dos termos anatômicos.

Os resultados ósseos e musculares foram documentados por meio de fotografias obtidas com câmera Nikon D90, com uma lente $35 \mathrm{~mm} 1.8$ e outra $60 \mathrm{~mm} 2.8$ e flashes de estúdio, sem fio. As fotografias dos ossos do animal adulto das figuras 2, 3 e 8 foram realizadas com câmera digital Olympus, modelo uD 800,S800, e para a fotografia da gastrália na figura 6 foi utilizada a câmera digital Samsung, modelo L200, ambos em modo automático.

\section{RESULTADOS}

Nos espécimes analisados não foi observada variação anatômica entre os indivíduos e tampouco entre os antímeros, tanto para os ossos, quanto para os músculos. No tronco do jacaré-do-Pantanal são encontrados os cortes comerciais filé de lombo (constituído pelos músculos epaxiais da região torácica, lombar e sacral, além do m. iliocostal), aparas (músculos latero-ventrais da parede torácica e abdominal) e o filé mignon (músculo sublombar e pélvico). Tais cortes têm como bases ósseas as vértebras torácicas, lombares e sacrais com as respectivas costelas, o esterno e a gastrália, além do osso coxal e do fêmur, não pertencentes ao tronco.

Considerando a localização, a característica dos músculos com ventres musculares delgados e curtos e inserções tendíneas longas, além da não utilização como cortes comerciais, alguns músculos do tronco não foram estudados. Não foram descritos nesta pesquisa os músculos intertransversais ( $\mathrm{mm}$. intertransversaii), além dos músculos 
epaxiais interespinhais ( $\mathrm{mm}$. interspinalis), multífidos (mm. multifidi) e espinhal (m. spinalis), os quais também não são desossados.

\section{Bases ósseas do filé de lombo}

As massas musculares que correspondem ao filé de lombo se fixam nas vértebras torácicas, lombares e sacrais, assim como nas correspondentes costelas.

As nove vértebras torácicas (VT) presentes em Caiman yacare são vértebras típicas, apresentam características semelhantes e estão associadas a nove pares de costelas torácicas. As VT possuem corpo cilíndrico, cuja extremidade cranial é côncava e a extremidade caudal é convexa, sendo consideradas procélicas. A superfície ventral do corpo possui o processo ventral (até a quarta VT), sendo ausente nas demais vértebras da região. 0 arco apresenta as incisuras vertebrais craniais e caudais, que formam os forames intervertebrais. Possuem processos articulares craniais (planos e voltados dorsalmente) e os caudais (planos e voltados ventralmente). Os processos transversos são alongados e achatados dorso-ventralmente, sua extremidade lateral é única nas duas primeiras VT e a partir da terceira VT, os processos transversos são bífidos e possuem duas áreas articulares, as fóveas costais do processo transverso. A fóvea costal mais cranial se articula com a cabeça da costela, enquanto a mais caudal com o tubérculo da costela. Na medida em que se dirigem caudalmente, a área cranial desloca-se no sentido caudal, ocorrendo a aproximação das duas áreas. Os processos espinhosos dirigem-se dorsalmente, são praticamente da mesma extensão, possuem um sulco mediano no ápice e suas extremidades dorsais apresen-
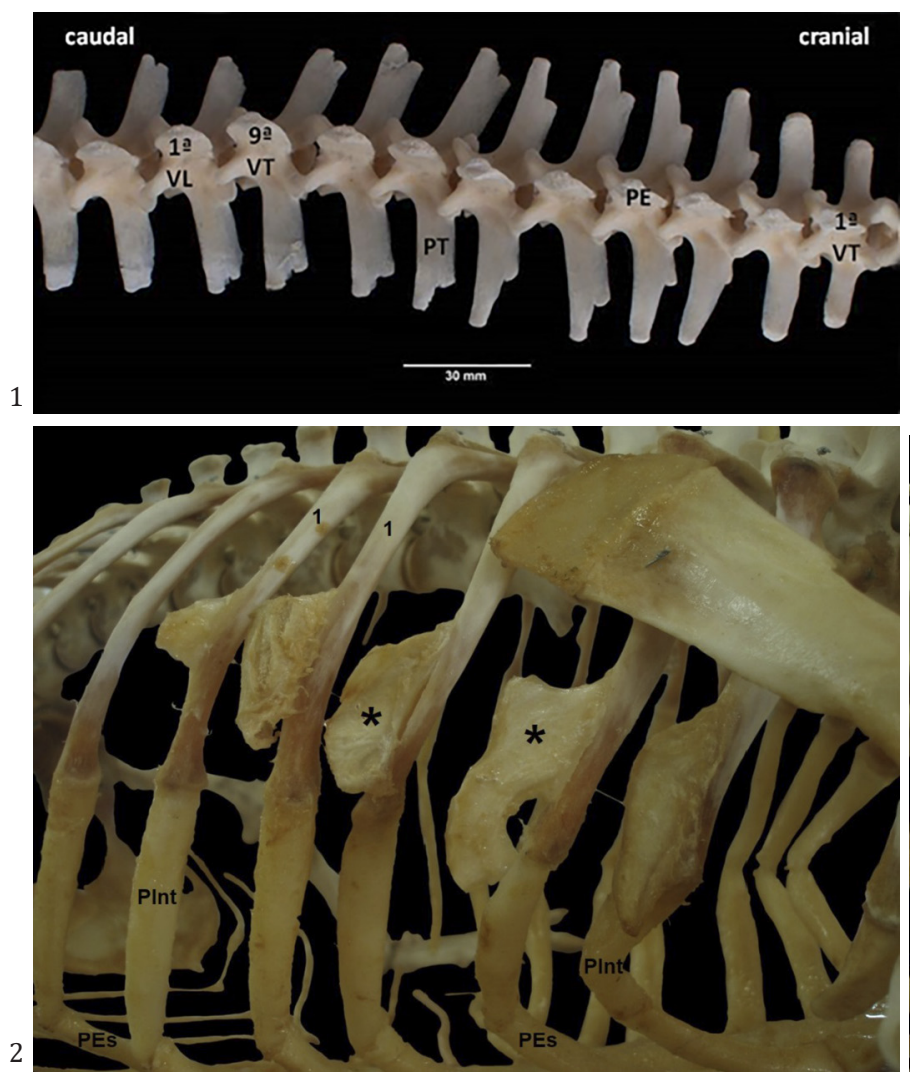

Fig.1. Vértebras torácicas e lombares de Caiman yacare juvenil, vista dorsal. $1^{\underline{a}}$ vértebra torácica ( $\left.1^{\underline{a}} \mathrm{VT}\right)$; processo espinhoso (PE); processo transverso (PT) com fóveas costais (setas); 9a

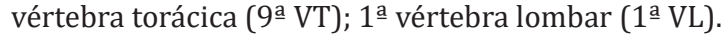

Fig.2. Esqueleto torácico de Caiman yacare adulto, vista cranio-lateral direita. Osso costal (1); porção esternal (PEs) e porção intermediária (PInt); das costelas torácicas; processos uncinados (*). Fonte: adaptada de Guimarães (arquivo pessoal, 2007).

Fig.3. Vértebras e costelas lombares $\left({ }^{*}\right)$ de Caiman yacare adulto, vista dorso-lateral esquerda. Gastralium caudal (setas); $2^{\mathrm{a}}$ vértebra lombar (2 $\left.{ }^{\underline{a}} \mathrm{VL}\right) ; 6^{\underline{a}}$ vértebra lombar (6 $\left.{ }^{\underline{a}} \mathrm{VL}\right)$. Fonte: adaptada de Guimarães (arquivo pessoal, 2007).

tam-se dilatadas formando um tubérculo (Fig.1).

Cada costela torácica é constituída por três porções, o a porção esternal. 0 osso costal possui uma extremidade vertebral (com uma cabeça, um colo e um tubérculo costal), parte intermediária na articulação costocondral. A cabeça até se tornarem indistintos. Da margem lateral do corpo, dorsalmente às articulações costocondrais, encontram-se placas fibrocartilaginosas dirigidas caudalmente, denomitelas. A porção intermediária e esternal são segmentos de cartilagem costal. A porção intermediária articula-se com a extremidade ventral do osso costal e a porção esternal dirina articulação esternocostal, sendo que a primeira articula-se com o esterno cartilaginoso e os segmentos ventrais da gunda à nona articulam-se com os cornos xifóides (Fig.2). são típicas e semelhantes entre si. Possuem corpo cilíndrico, são procélicas, não possuem crista ventral e nem craniais e caudais, que formam os forames intervertebrais. Os processos articulares craniais e caudais são planos e setem comprimento simétrico e os processos transversos são alongados, achatados dorso-ventralmente e nas quatro primeiras VL possuem nas suas extremidades laterais áreas (fóveas costais dos processos transversos) para articulação

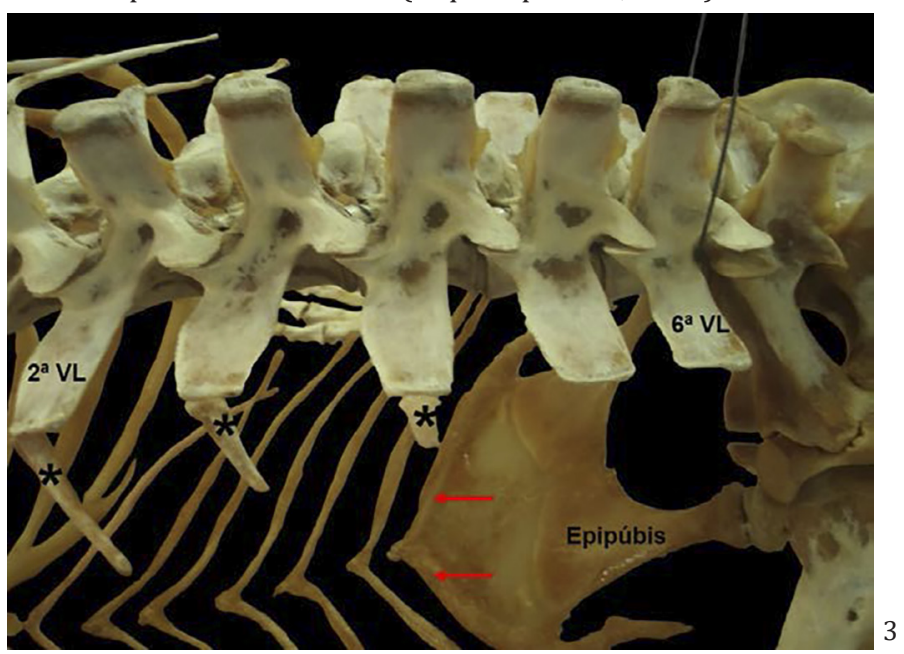
um corpo e uma extremidade ventral, articulando-se com a 
com as costelas lombares.

As costelas lombares são pequenas, pareadas e formadas somente por um segmento ósseo (Fig.3), dirigem-se caudalmente e vão reduzindo significativamente de tamanho de VL1 a VL4, não sendo encontradas em VL5 e VL6.

As duas vértebras sacrais (VS) de C. yacare são independentes (não fusionadas) e possuem o corpo cilíndrico (Fig.4), à semelhança da região torácica. No entanto, a primeira VS possui a extremidade cranial do corpo côncava e a extremidade caudal plana. Já na segunda VS, a extremidade cranial do corpo é plana e a extremidade caudal é côncava. 0 arco das VS apresenta processos articulares craniais (dirigidos dorso-medialmente) e caudais (dirigidos ventro-caudalmente). Os processos espinhosos são semelhantes aos das VL, enquanto os processos transversos são curtos e se articulam com as costelas sacrais.

As costelas sacrais são ossos pares, bem desenvolvidos, possuem aspecto piramidal e se projetam lateralmente das VS, cujo vértice articula-se com o corpo vertebral (ventralmente) e com o processo transverso (dorsalmente) e cuja base está fixada ao ílio (Fig.4).

\section{Bases musculares do filé de lombo}

O filé de lombo é constituído pelos músculos semiespinhal, longuíssimo e iliocostal.

O M. semiespinhal (m. semispinalis) é o músculo epaxial mais medial que participa desse corte. É constituído por duas partes (medial e lateral), designadas respectivamente $\mathrm{m}$. articuloespinhal e $\mathrm{m}$. tendinoarticular, cujo direcionamento das fibras é oposto. Está localizado entre o $\mathrm{m}$. espinhal (medialmente) e o m. longuíssimo dorsal (lateralmente). Septos triangulares de tecido conjuntivo estão presentes entre as duas partes, delimitando-as e constituindo

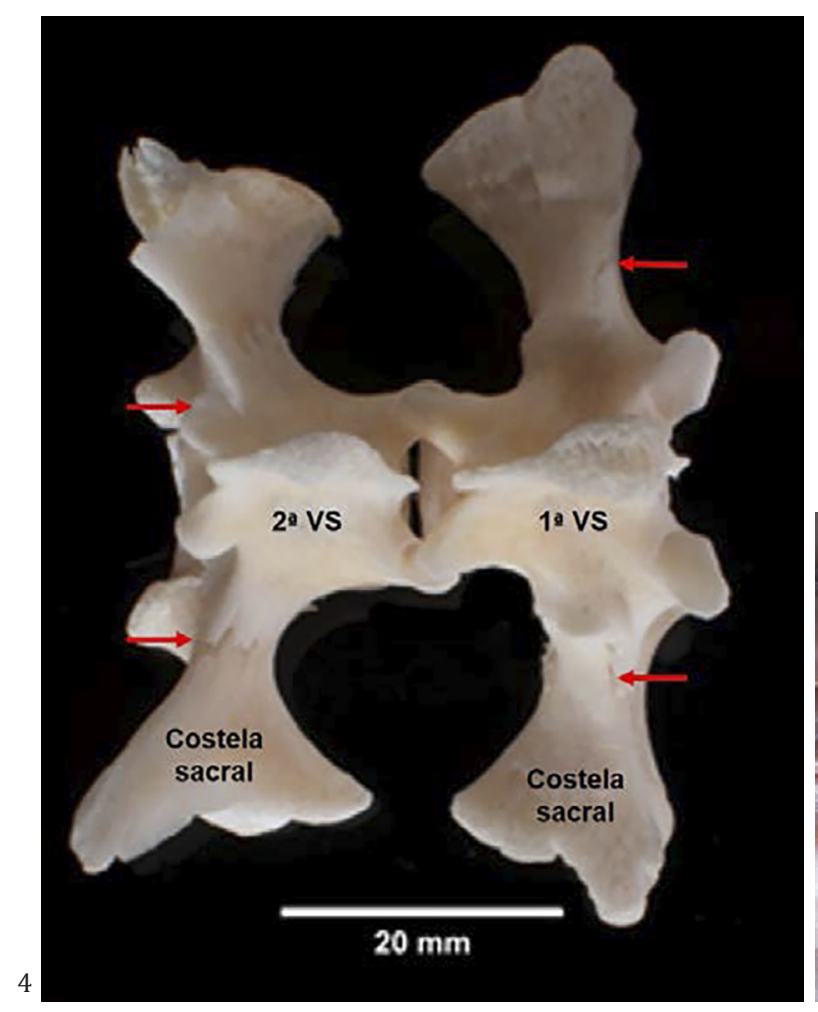

Fig.4. Vértebras e costelas sacrais de Caiman yacare juvenil, vista dorsal. Limite entre processo transverso e costela sacral (setas).

Fig.5. Tronco de Caiman yacare juvenil, vista dorsal. M. articuloespinhal (ArEs); intersecções tendíneas (setas) do m. iliocostal torácico (IcTo); m. longuíssimo torácico (LoTo) formado por cones de miosseptos imbricados ( $\left(_{*}\right)$;m. Tendinoarticular (TeAr). Esquema se refere à região anatômica do corte comercial.

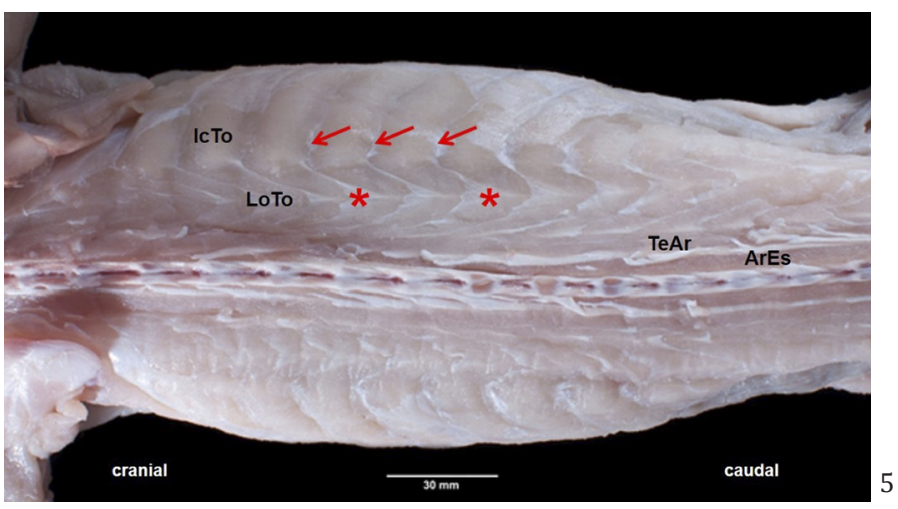


Está apoiado ao longo dessas três regiões sobre a parte mais lateral dos processos transversos das vértebras torácicas e lombares, enquanto na região sacral se apoia nas costelas sacrais. 0 tecido conjuntivo dos cones de miossepto fixa a face ventral desse músculo nos processos transversos das VT, VL e nas costelas sacrais. Medialmente e lateralmente, por meio de sua fáscia superficial, se ancora, respectivamente, no septo intermuscular dorsal e no septo transverso.

O m. iliocostal (m. iliocostalis) estende-se de forma contínua nas regiões cervical (m. iliocostal cervical), torácica (m. iliocostal torácico) e lombar (m. iliocostal lombar), sendo que as porções torácica e lombar constituem o m. iliocostal dorsal ou do tronco. Este músculo é constituído por segmentos de ventres musculares sucessivos, delimitados por intersecções tendíneas. Suas fibras musculares, orientadas longitudinalmente, percorrem o espaço intercostal, delimitadas por septos conjuntivos que se inserem na face latero-caudal das costelas (Fig.5). No tronco, está situado latero-ventralmente ao m. longuíssimo dorsal, separado deste pelo septo transverso. Cranialmente, está localizado profundamente ao $\mathrm{m}$. serrátil superficial e, ventro-caudalmente, faz relação de sintopia com os músculos oblíquos e transverso abdominal, cuja fáscia serve de inserção para esses músculos abdominais. Medialmente, o m. iliocostal está fixado ao m. longuíssimo dorsal pelo septo transverso. Lateralmente, sua fáscia lombodorsal serve de inserção ao músculo oblíquo abdominal externo superficial e na sua fáscia profunda se insere o músculo oblíquo abdominal externo profundo, oblíquo abdominal interno e o transverso abdominal. Apoia-se sobre as costelas torácicas e nas três primeiras lombares. Nas torácicas, se estende desde as articulações costovertebrais até a articulação entre o osso costal e o segmento intermediário das costelas, revestindo inclusive os processos uncinados. Sua extremidade caudal se fixa por meio de uma aponeurose na tuberosidade sacral na superfície cranio-medial do ílio.

\section{Bases ósseas do corte aparas}

Esse corte é constituído pelos músculos dispostos em posição latero-ventral nas paredes torácica e abdominal, tendo como base óssea as costelas torácicas, lombares e sacrais (descritas no filé de lombo), a gastrália, o esterno e o epipúbis.

A gastrália (gastralia) em C. yacare é formada por um conjunto de estruturas ósseas cilíndricas, esbranquiçadas, dispostas aos pares, formando de seis a sete linhas incrustadas na musculatura da porção ventral da parede abdominal. Cada linha é composta por quatro segmentos, sendo dois mediais e dois laterais. Esses segmentos (gastralium) apresentam disposição metamérica e, portanto, são paralelos. Os segmentos estão conectados entre si por membranas, sendo a mais conspícua a membrana existente entre o último segmento e o epipúbis (parte óssea do púbis). Os segmentos mediais e laterais apresentam quatro faces (dorsal, ventral, cranial e caudal) e duas extremidades (medial e lateral). Observou-se na presente pesquisa que o segmento medial possui menor comprimento e se articula com o seu contralateral na linha mediana ventral, pelas suas extremidades mediais, em um ângulo obtuso formado entre suas margens caudais. Esse arranjo confere aos segmentos mediais (direito e esquerdo) o formato da letra V. 0 segmento lateral é maior e articula-se, de forma imbricada, na face cranial do segmento medial (Fig.6).

0 esterno é predominantemente cartilaginoso e constituído por três partes: o episterno, o esterno cartilaginoso e os cornos xifóides. O episterno é uma projeção óssea mediana, cilíndrica e alongada, que constitui a porção mais cranial do esterno. Sua extremidade cranial atinge o nível da oitava vértebra cervical e sua extremidade caudal projeta-se na superfície ventral do esterno cartilaginoso. 0 esterno cartilaginoso tem aspecto quadrangular, achatado dorso-ventralmente e suas margens laterais possuem duas superfícies articulares, uma maior em forma de sulco destinado à face articular da margem medial da asa do coracoide, e a outra caudal, de forma arredondada (incisura costal), para articulação com o primeiro par de costelas torácicas. Os cornos xifoides consistem de duas projeções cartilaginosas, alongadas, que contatam cranialmente com a porção caudal do esterno cartilaginoso e divergem gradualmente em sentido caudal. Sua borda medial une-se com o do lado oposto no plano mediano e sua borda lateral possui incisuras costais para articulação com os segmentos esternais das demais costelas torácicas. Entre os dois cornos, há uma projeção na parte caudal (Fig.7).

O epipúbis corresponde à porção óssea do púbis. É um osso achatado dorso-ventralmente, de aspecto triangular, com a base disposta cranialmente e o ápice caudalmente. Sua base apresenta uma cartilagem plana, que se articula cranialmente com a gastralium mais caudal através de uma membrana. Apresenta duas faces (dorsal e ventral), três margens (cranial, medial e lateral) e três ângulos (medial, lateral e caudal). 0 ângulo caudal é o mais proeminente e articula-se com a cabeça do ísquio. 0 eixo longo (maior) do

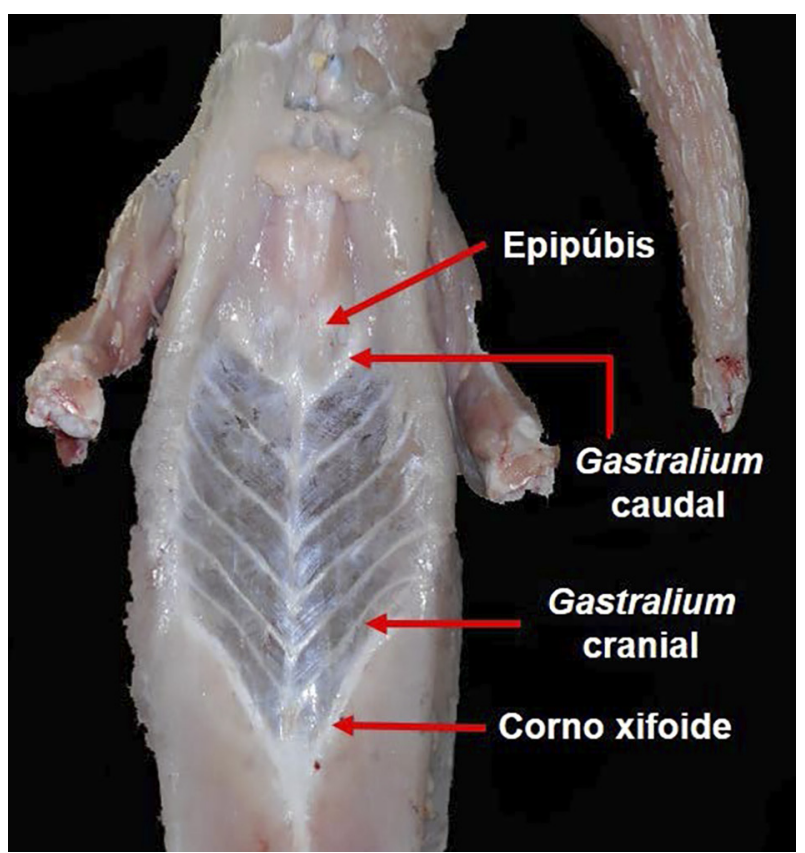

Fig.6. Tronco de Caiman yacare juvenil durante a esfola para evidenciação da gastrália, vista ventral. 


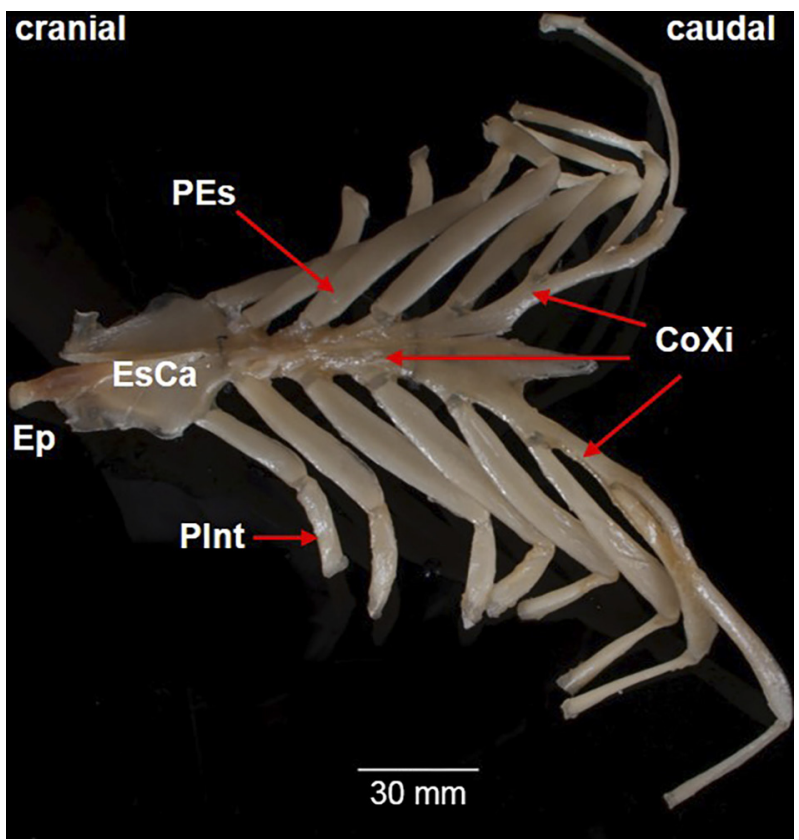

Fig.7. Esterno de Caiman yacare juvenil, vista ventral. Corno xifoide (Coxi); Episterno (Ep); Esterno cartilaginoso (EsCa); porção esternal (PEs) e porção intermediária (PInt) das costelas torácicas.

epipúbis está dirigido cranio-ventro-medialmente e une-se com o seu contralateral no plano mediano através de uma articulação fibrocartilagínea (Fig.8).

\section{Bases musculares do corte Aparas}

Este corte é constituído pelos músculos serrátil (superficial e profundo), grande dorsal, oblíquo abdominal externo (superficial e profundo), reto abdominal, além da maior parte do peitoral (superficial e profundo) e as partes dos $\mathrm{mm}$. oblíquo abdominal interno e transverso abdominal localizadas caudalmente à última costela torácica na região abdominal lateral. Nessa região corporal não são desossadas e, portanto, não utilizadas como corte comercial, as partes dos $\mathrm{mm}$. oblíquo abdominal interno e transverso abdominal relacionadas às costelas torácicas, assim como os músculos intercostais.

O m. serrátil ( $\boldsymbol{m}$. serratus) é um músculo plano, em forma de leque, constituído por uma parte superficial e outra profunda. O M. serrátil superficial (m. serratus superficialis), em sua face profunda, relaciona-se ao m. serrátil profundo e ao $\mathrm{m}$. iliocostal torácico. Ventro-medialmente, esse músculo se relaciona ao m. peitoral e, caudalmente, ao m. oblíquo abdominal externo superficial. Sua extremidade cranial se fixa de forma aponeurótica por toda a extensão da margem caudal da escápula e sua cartilagem (Fig.9). Suas fibras se direcionam caudalmente para se inserir de forma serrilhada na fáscia superficial, entre o $\mathrm{m}$. iliocostal torácico e a parte superficial do m. oblíquo abdominal externo, na altura da articulação entre o osso costal e o segmento intermediário, na margem caudal das quatro primeiras costelas torácicas. 0 M. serrátil profundo ( $m$. serratus profundus) está localizado entre a face medial da escápula e a parede lateral do tórax. Suas fibras emergem

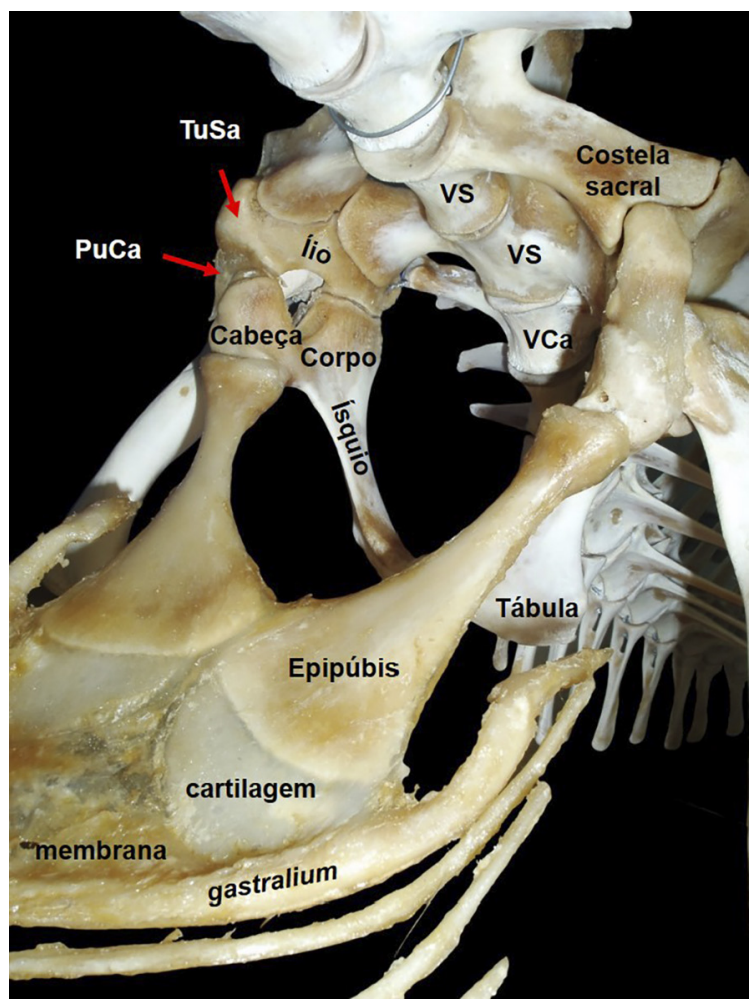

Fig.8. Epipúbis (in situ) de Caiman yacare adulto, vista dorsolateral esquerda, onde se observam gastralium caudal, ílio, ísquio, púbis cartilaginoso (PuCa); tuberosidade sacral (TuSa); vértebra caudal (VCa); vértebra sacral (VS) e costela sacral. Fonte: adaptada de Guimarães (arquivo pessoal, 2007).

da região dorso-medial da escápula e se expandem cranio-caudalmente até atingir a parede lateral do tórax, onde se inserem de forma serrilhada na parte ventral da espessa fáscia que reveste o m. iliocostal, entre a primeira e a terceira costela torácica.

O m. grande dorsal (m. latissimus dorsi) é um músculo triangular, localizado superficialmente na região latero-caudal da escápula, cujo ventre muscular recobre o m. redondo maior e a parte cranial do $\mathrm{m}$. serrátil superficial

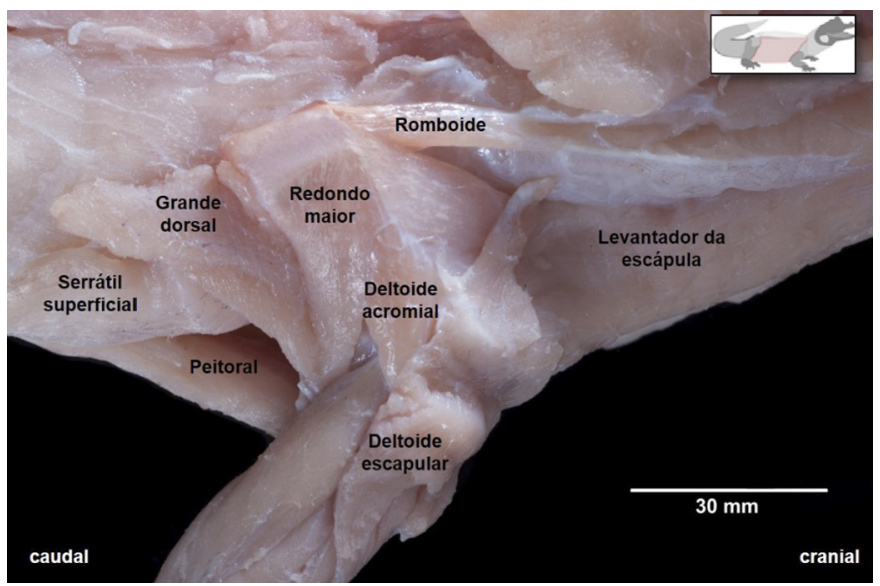

Fig.9. Músculos do cíngulo do membro torácico de Caiman yacare juvenil, vista dorso-lateral direita. Esquema se refere à região anatômica do corte comercial. 
(Fig.9). Devido ao rompimento parcial de sua fixação no tronco, em virtude da esfola realizada nos animais, essa não pôde ser descrita. Já sua extremidade ventral se insere por meio de um tendão longo, que se une ao tendão do m. redondo maior, em uma crista existente entre a margem e a face dorsal, na extremidade medial do úmero. Este tendão de inserção localiza-se profundamente aos dois tendões de origem do m. tríceps braquial porção longa caudal.

$0 \mathrm{~m}$. peitoral (m. pectoralis) é constituído por duas porções, o superficial (maior) e o profundo (menor), cujas fibras se mesclam. $0 \mathrm{~m}$. peitoral profundo está localizado dorsalmente ao m. peitoral superficial (Fig.10). Com exceção da porção mais cranial desse músculo, que participa do corte sobrecoxa no membro torácico, o restante faz parte do corte aparas. O M. peitoral superficial (m. pectora-

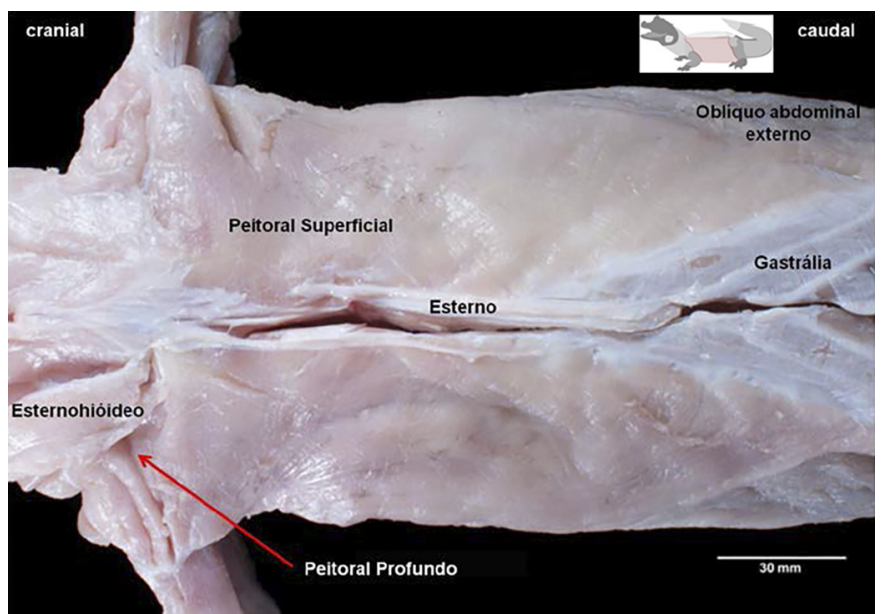

Fig.10. Tronco de Caiman yacare juvenil, vista ventral, onde se verificam os músculos peitorais, oblíquo abdominal externo e esternohioideo, além do esterno e gastrália. Esquema se refere à região anatômica do corte comercial. lis superficialis) é um músculo plano e largo, localizado na superfície ventral do tronco, cranialmente à gastrália e ao $\mathrm{m}$. reto abdominal e ventralmente à parte superficial do m. oblíquo abdominal externo. No seu terço cranial, as fibras estão dispostas transversalmente e, no restante, se posicionam obliquamente. Cranialmente, se relaciona com a porção caudal do m. esternoioideo, e caudo-lateralmente se une à fáscia do m. troncocaudal, ao nível da extremidade lateral da primeira gastralium. Profundamente a esse músculo encontram-se corpos adiposos. Está inserido medio-caudalmente ao longo da superfície ventral paramediana do esterno cartilaginoso e dos cornos xifoides. Sua margem cranio-lateral insere na crista deltopeitoral do úmero, juntamente com a inserção do m. supracoracoideo. 0 M. peitoral profundo ( $m$. pectoralis profundus) é um músculo plano, estreito, com fibras dispostas transversalmente, ocupando a superfície ventral do coracoide. Sua parte cranio-medial posiciona-se dorsalmente à parte esternoatlantical do m. esternomastoide. Sua inserção medial fixa na superfície dorso-lateral do episterno e na margem lateral do esterno cartilaginoso. Sua inserção lateral insere na crista deltopeitoral do úmero.

Os músculos abdominais (Fig.11A-D) também participam do corte aparas em $C$. yacare, sendo eles o m. oblíquo abdominal externo (superficial e profundo), reto abdominal, e parte dos mm. oblíquo abdominal interno e transverso abdominal. Esses músculos formam a parede latero-ventral da região abdominal. A maior parte dessa parede possui estruturas ósseas e cartilaginosas que sustentam esses músculos (costelas, gastrália, esterno e epipúbis); a exceção é a região latero-caudal, formada somente por ventres musculares. Esses músculos abdominais são planos e diferenciam entre si quanto ao direcionamento de fibras,

Fig.11. (A) Abdômen de Caiman yacare juvenil, vista lateral direita superficial e (B-D) profunda. M. intercostal (IC); m. oblíquo abdominal interno (OAI); m. oblíquo abdominal externo profundo (OAEPr); m. oblíquo abdominal externo superficial (OAESu); m. peitoral superficial $(\mathrm{PeSu}) ; \mathrm{m}$. reto abdominal (ReAb); m. transverso abdominal (TraAb). Esquema se refere à região anatômica do corte comercial (A-D).
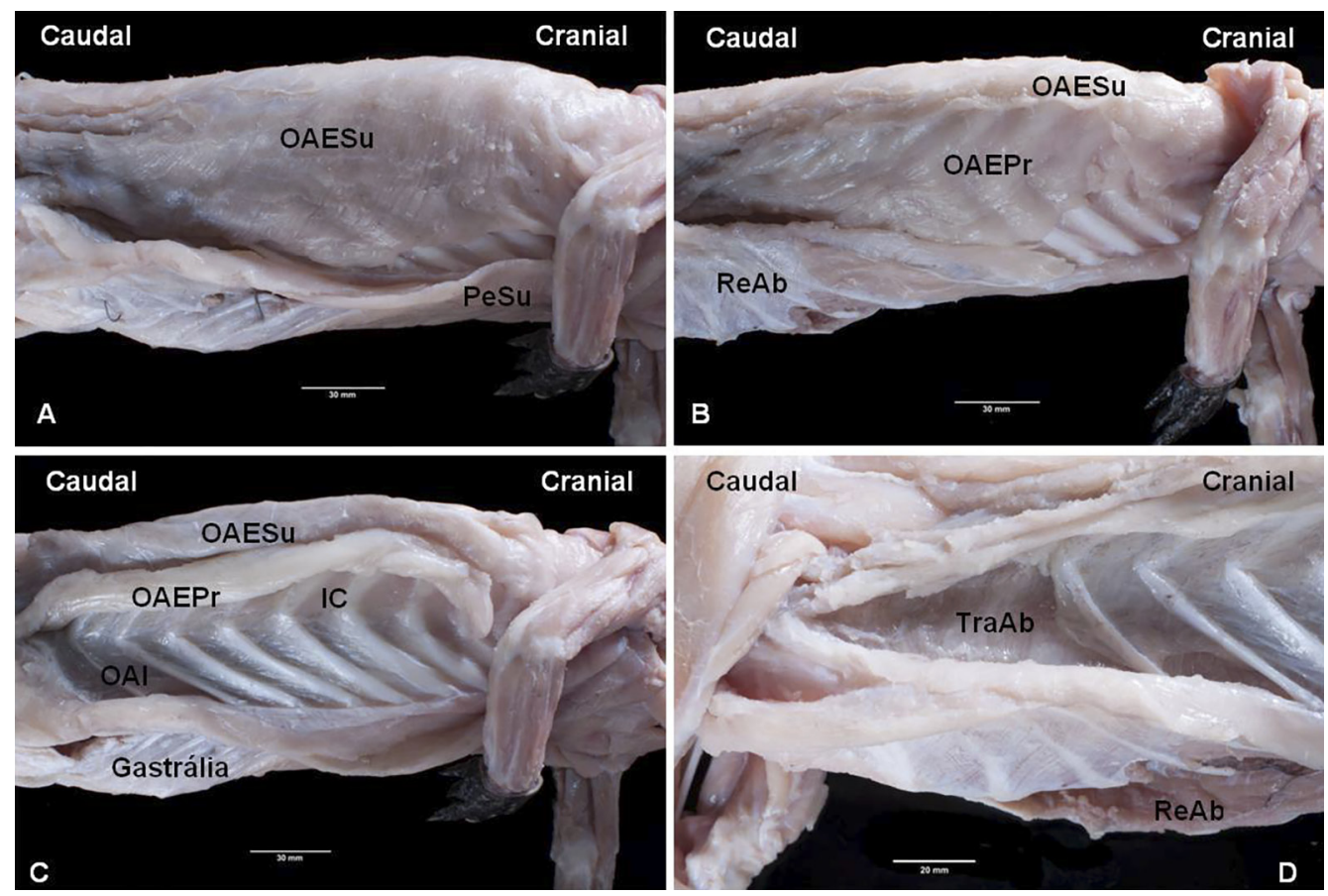
localização e pontos de fixação.

O m. oblíquo abdominal externo ( $m$. obliquus externus abdominis) possui duas camadas, a superficial e a profunda (Fig.11A-C).

$\mathrm{O}$ m. oblíquo abdominal externo superficial $(\mathrm{m}$. obliquus externus abdominis superficialis) é o músculo mais superficial da parede lateral do tronco, estendendo-se ao longo de toda a região toraco-lombar, ventralmente ao $\mathrm{m}$. iliocostal, caudalmente ao $\mathrm{m}$. serrátil superficial, com fibras dispostas caudo-ventralmente. Sua margem dorsal insere na fáscia do $\mathrm{m}$. iliocostal da primeira à nona costela torácica. Ao longo de sua margem ventral, apresenta uma inserção cranial e outra caudal. A margem ventral cranial insere profundamente ao m. peitoral superficial, se fixando na superfície ventro-lateral do esterno cartilaginoso e dos cornos xifoides, a margem ventral caudal se fixa por aponeurose na superfície lateral da gastrália, cruza a face superficial do m. reto abdominal e se insere na linha mediana ventral. A extremidade caudal possui dois pontos de fixação; um dorsal, por meio de tendão, se fixa no ísquio, ao nível da sua articulação com o epipúbis, ventralmente ao tendão de origem do m. ambiens maior; a fixação caudo-ventral se dá por meio de uma cinta de tecido conjuntivo na extremidade caudo-lateral da tábula do ísquio.

0 m. oblíquo abdominal externo profundo $(\mathrm{m}$. obliquus externus abdominis profundus) é mais espesso e apresenta inclinação das suas fibras mais acentuada que o superficial. Localiza-se entre os $\mathrm{mm}$. intercostais (medialmente), a porção superficial do m. obliquo externo (lateralmente) e o m. serrátil superficial (cranialmente). Sua margem dorsal é constituída por feixes digitiformes, que se inserem na face latero-caudal das costelas, juntamente com as intersecções tendíneas do m. iliocostal, da primeira à nona costela torácica. Sua extremidade caudal se fixa por tendões no ísquio, ao nível da sua articulação com o epipúbis, entre as origens dos m. ambiens maior e menor. A fixação da sua margem ventral é compartilhada pela mesma aponeurose do m. obliquo abdominal externo superficial.

O M. oblíquo abdominal interno ( $\mathrm{m}$. obliquus internus abdominis) é um músculo delgado, cujas fibras ocupam o espaço intercostal entre os segmentos intermediário e esternal das costelas torácicas. Constitui-se de fibras perpendiculares entre os segmentos de sustentação, formando a parede interna no espaço intercostal, contribuindo ainda para a formação da parede latero-caudal do abdômen. Está localizado entre o m. oblíquo abdominal externo profundo e os m. intercostais (superficialmente) e m. transverso abdominal (profundamente). Sua margem dorsal se fixa na fáscia profunda do $\mathrm{m}$. iliocostal e a maior parte do seu ventre muscular na margem caudal dos segmentos intermediário e esternal das costelas torácicas. Sua margem ventral se une à aponeurose do $\mathrm{m}$. transverso abdominal, que cruza a superfície dorsal do m. reto abdominal, entre suas partes superficial e profunda, em direção à linha mediana. Sua extremidade caudal se fixa por meio de um tendão no ísquio, ao nível da articulação com o epipúbis (Fig.11C).

O M. transverso abdominal (m. transversus abdominis) é um músculo extenso e fino, com fibras dispostas transversalmente, responsável pelo revestimento interno da parede lateral do tronco (tórax e abdômen), ao longo da superfície medial dos segmentos intermediário e esternal das costelas torácicas, até a entrada da pelve. Está situado profundamente ao m. oblíquo abdominal interno, entre este e a serosa (Fig.11D). Apresenta-se mais espesso entre a primeira e a quarta costela. Sua margem dorsal fixa-se por toda extensão da fáscia profunda do m. iliocostal. $\mathrm{Na}$ margem ventral, une-se à aponeurose do m. oblíquo abdominal interno, cruza a superfície dorsal do m. reto abdominal, exceto a sua parte profunda, para se inserir na linha mediana ventral. Sua extremidade cranial se insere na superfície dorsal do episterno e na superfície ventral do coracoide, sua extremidade caudal se fixa por aponeurose na face lateral do epipúbis.

$0 \mathrm{~m}$. reto abdominal (m. rectus abdominis) ocupa toda a extensão da gastrália, constituído por uma parte maior, plana e superficial e outra em forma de cinta, localizada profundamente em posição paramediana (Fig.11B; D). A parte mais superficial desse músculo ocupa os espaços entre os segmentos da gastrália, conferindo o aspecto segmentado aos seus ventres musculares. Já a parte profunda se diferencia pela sua espessura e pela separação que as aponeuroses do m. oblíquo abdominal interno e do $\mathrm{m}$. transverso abdominal propiciam ao se direcionarem para a linha mediana ventral. A face ventral do m. reto abdominal é revestida pela aponeurose do $\mathrm{m}$. oblíquo abdominal externo (superficial e profundo) e a sua face dorsal é parcialmente revestida pela aponeurose do músculo oblíquo abdominal interno e do m. transverso abdominal, com exceção da sua parte mais profunda. Faz sintopia com o m. peitoral superficial (cranialmente), com os músculos pélvicos (caudalmente) e com os demais músculos abdominais (lateralmente). Sua extremidade cranial se fixa na margem caudal dos cornos xifoides e sua extremidade caudal fixa na margem cranial do último segmento da gastrália. Sua margem medial, por meio de aponeurose, estende-se até a linha mediana ventral onde se une ao seu contralateral.

\section{Bases ósseas do filé mignon}

Este corte é constituído pelo m. puboisquiofemoral interno cranial, localizado na região sublombar, e pelo $\mathrm{m}$. troncocaudal, disposto superficialmente na superfície ventral da pelve. Tem como base óssea as vértebras lombares, sacrais e a gastrália, (descritas junto aos cortes filé de lombo e aparas), além do osso coxal e o fêmur.

O osso coxal é constituído pelos ossos ílio, ísquio e púbis, cuja articulação delimita uma depressão na face lateral desses ossos denominada acetábulo (Fig.12). No centro dessa depressão, observa-se o forame acetabular. 0 ílio é a parte mais dorsal do coxal; compõe a porção dorsal do acetábulo e possui uma asa e um corpo. A asa possui duas faces, medial e lateral, e o contato dorsal entre elas forma a crista ilíaca, que é projetada lateralmente e une duas tuberosidades (sacral e coxal). A face medial da asa articula-se com as duas costelas sacrais. A tuberosidade sacral, voltada cranialmente, é formada por uma parte dorsal, maior e mais lateral, e outra ventral, menor. Ambas se articulam com o púbis cartilaginoso, que por sua vez se articula com a cabeça do ísquio. Este conjunto formado pela articulação 


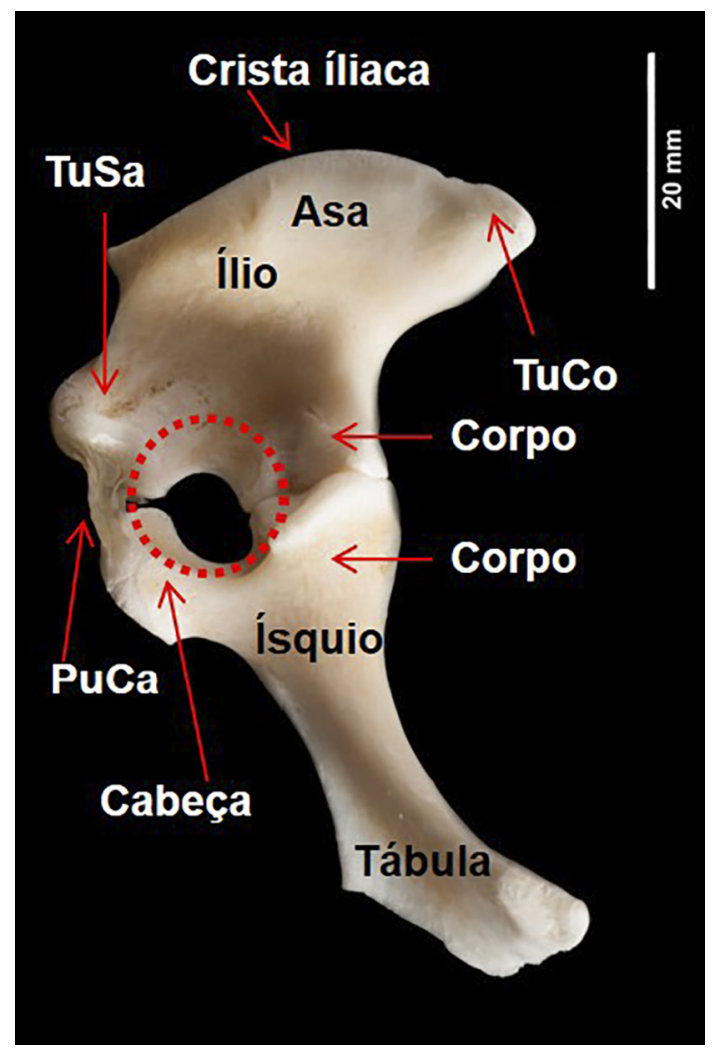

Fig.12. Osso coxal de Caiman yacare juvenil, vista lateral esquerda. Púbis cartilaginoso (PuCa); tuberosidade coxal (TuCo) e sacral (TuSa). Acetábulo (linha pontilhada).

da tuberosidade sacral, o púbis cartilaginoso e a cabeça do ísquio formam o limite cranial do forame acetabular. $\mathrm{Na}$ crista ilíaca, caudalmente à tuberosidade sacral, existe uma projeção denominada espinha sacral. A tuberosidade coxal é voltada caudalmente e, em sua porção ventral, surge a incisura isquiática menor. 0 corpo do ílio, na sua extremidade ventral, articula-se com o corpo do ísquio e forma o limite caudal do forame acetabular. Na face articular do corpo do ílio, existe um recorte na margem lateral dessa superfície articular chamada incisura acetabular.

O ísquio é constituído por uma cabeça, um colo, um corpo e uma tábula. A cabeça, voltada cranialmente, articula-se dorsalmente com o púbis cartilaginoso e ventro-cranialmente com o epipúbis. 0 colo forma o limite cranio-ventral do forame acetabular e une a cabeça ao corpo do ísquio. 0 corpo do ísquio forma o limite caudo-ventral do forame acetabular. A superfície articular do corpo do ísquio se divide em duas áreas triangulares, uma medial, que se articula com o corpo do ílio, e outra lateral que serve para articulação com a cabeça do fêmur. Do corpo emerge a tábula, que se arqueia em sentido ventro-medial até o encontro da tábula contralateral. A tábula possui duas faces, dorsal e ventral, além de três margens, cranial, medial e caudal. A margem caudal forma a incisura isquiática maior. A margem medial da tábula, em sua parte cranial, forma juntamente com seu contralateral a sínfise isquiática, e na parte caudal o arco isquiático.

0 púbis é constituído por uma porção cartilaginosa e uma porção óssea ou epipúbis, descrito anteriormente no
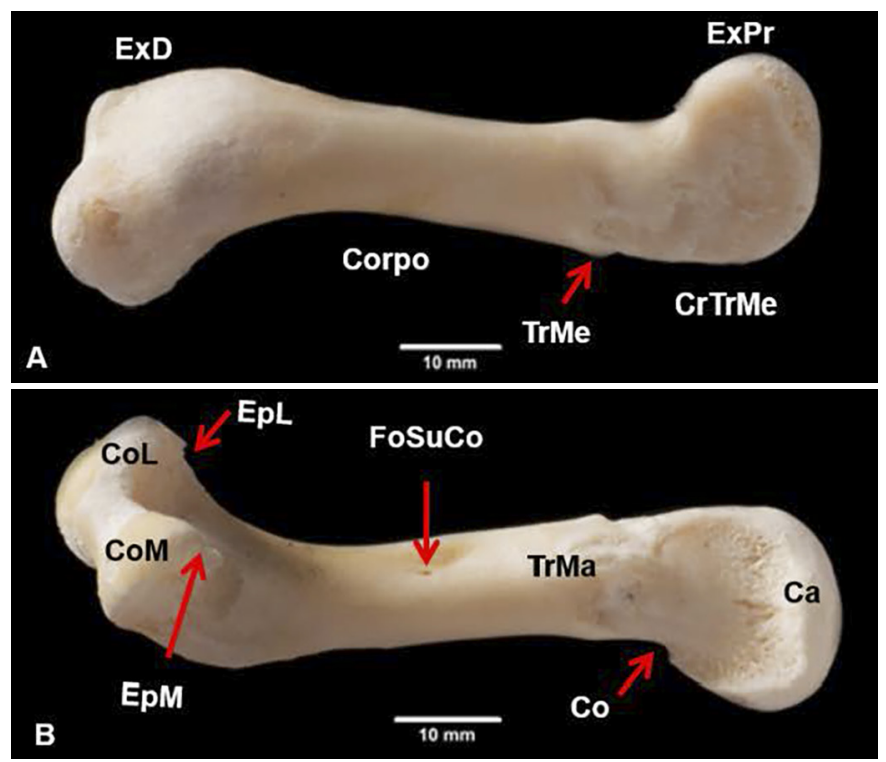

Fig.13. (A) Face dorso-caudal e (B) ventro-caudal do fêmur esquerdo de Caiman yacare juvenil. Cabeça (Ca); colo (Co); côndilo lateral (CoL); côndilo medial (CoM); crista do trocânter menor (CrTrMe); epicôndilo lateral (EpL); epicôndilo medial (EpM); extremidade distal (ExD); extremidade proximal (ExPr); fossa supracondilar (FoSuCo); trocânter maior (TrMa); trocânter menor (TrMe).

corte aparas. A porção cartilaginosa é uma pequena massa de cartilagem entre o ílio (dorsal) e a cabeça do ísquio (ventral) que forma a margem cranial do acetábulo.

0 fêmur é um osso longo, que representa a região femoral. Está disposto obliquamente ao tronco, com seu eixo longitudinal dirigido cranio-lateralmente. Possui um corpo com quatro faces, dorsal, ventral, cranial e caudal, além de duas extremidades, proximal e distal. A extremidade proximal apresenta uma cabeça, alongada cranio-caudalmente, um colo e um discreto trocânter menor no sentido dorso-caudal, precedido por um forame nutrício entre a extremidade proximal e o corpo. Na margem caudo-dorsal, entre a cabeça e o trocânter menor, há uma crista para inserção muscular, denominada crista do trocânter menor. 0 corpo se apresenta arqueado dorsalmente, resultando em uma rotação da extremidade distal. Na margem caudo-ventral do corpo, observa-se uma crista que se estende até o epicôndilo lateral. Possui um trocânter maior na face cranio-ventral do corpo, que equivale ao quarto trocânter (Wilhite 2003, Otero et al. 2010). A fossa supracondilar é pequena e está posicionada ventro-caudalmente na metade do corpo. A extremidade distal possui um côndilo medial e outro lateral, que é maior, e na face cranial dos côndilos encontra-se um sulco intercondilar. Na face caudal da extremidade distal, proximalmente a cada côndilo, encontram-se duas cristas ósseas, denominadas de epicôndilo medial e outro lateral, sendo o lateral maior (Fig.13).

\section{Bases musculares do filé mignon}

$0 \mathrm{~m}$. puboisquiofemoral interno cranial (m. puboischiofemoralis internus cranialis) está localizado cranial- 


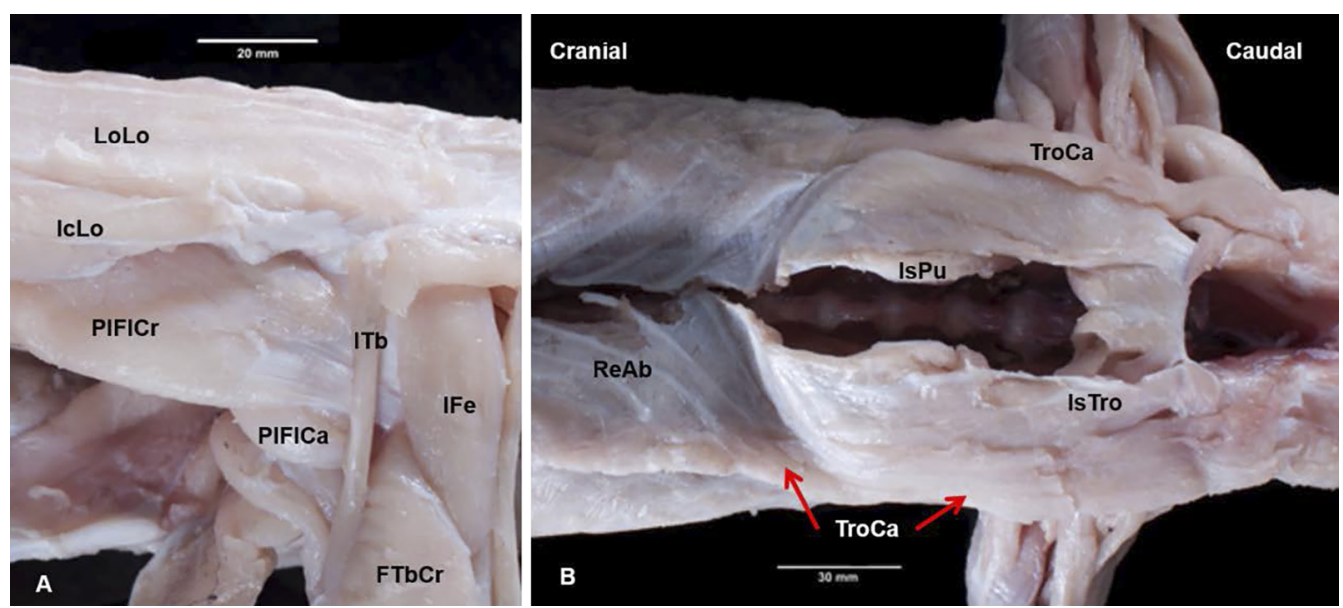

Fig.14. (A) Região lombar vista lateral esquerda e (B) da região pélvica vista ventral de Caiman yacare juvenil. Em A: m. femorotibial cranial (FTbCr); m. iliocostal lombar (IcLo); m. iliofemoral (IFe); m. iliotibial (ITb); m. puboisquiofemoral interno caudal (PIFICa); m. puboisquiofemoral interno cranial (PIFICr) e m. longuíssimo lombar (LoLo). Em B: m. isquiopúbis (IsPu); m. isquiotronco (IsTro); m. reto abdominal (ReAb) e m. troncocaudal (TroCa). Esquema se refere à região anatômica do corte comercial (A-B).

mente na região lateral dos corpos das vértebras lombares VL2 a VL6. Trata-se de um músculo triangular robusto, delimitado em sua extremidade caudal por dois grandes corpos adiposos, um na sua margem medial separando-o da porção caudal, e outro na sua margem lateral, próximo ao local em que emerge da cavidade abdominal. Localiza-se no teto da cavidade abdominal, profundamente à aponeurose de fixação dos músculos da parede abdominal e aos mm. iliocostal (dorsalmente) e transverso abdominal (dorso-lateralmente). Suas fibras se dirigem latero-caudalmente pelo teto da cavidade abdominal, por onde emergem para se inserir no fêmur (Fig.14A). Fixa-se medialmente, por aponeurose, no ângulo formado pelo processo transverso e respectivo corpo vertebral. Sua inserção caudal se dá de forma ampla, por meio de dois largos tendões, um dorsal, mais curto, e outro ventral, mais longo, que passam na superfície lateral do acetábulo. Esses tendões passam profundamente aos $\mathrm{mm}$. iliotibial cranial e médio para se inserirem profundamente ao $\mathrm{m}$. iliofemoral. 0 tendão dorsal se insere no trocânter menor e o ventral distalmente a ele, na face dorso-cranial, no limite entre a extremidade e o corpo do osso.

O M. troncocaudal ( $m$. truncocaudalis) também é comercializado como filé mignon. Juntamente com os $\mathrm{mm}$. isquiopúbis e isquiotronco, ocupa a região pélvica ventral, desde a parte caudal da gastrália e epipúbis até a margem caudal da cloaca. Tais músculos compartilham fibras de modo que a separação entre eles é parcial. Todos são músculos planos, sendo as fibras dispostas longitudinalmente, no sentido cranio-caudal. $0 \mathrm{~m}$. troncocaudal é o mais superficial e lateral músculo da superfície ventral da pelve. Estende-se da extremidade lateral do segundo segmento lateral da gastrália até a margem caudo-lateral da cloaca. Localiza-se entre o m. ilioisquiocaudal (caudalmente), o m. peitoral superficial (cranialmente) e o m. oblíquo abdominal externo superficial (dorsalmente). Sua inserção dorso-cranial se fixa nas cinco últimas linhas gastraliais, entre a extremidade lateral do gastralium e o limite ventral do m. obliquo abdominal externo superficial. Sua extremidade caudal se une por meio de intersecção tendínea na superfície ventral da extremidade cranial do m. ilioisquiocaudal (Fig.14B).

\section{DISCUSSÃO}

\section{Bases ósseas do filé de lombo}

A presença de nove VT e seis VL em Caiman yacare corresponde às 15 vértebras dorsais descritas por Lima et al. (2011) que, ao estudar a esqueletogênese em embriões dessa espécie, considerou que as vértebras dorsais apresentam morfologia similar. Por sua vez, Reese (2000) descreveu a ocorrência de 10 VT e cinco VL em $A$. mississippiensis. Essa variação provavelmente se deve à dificuldade de identificação da primeira VT, sendo que no presente trabalho utilizou-se o critério estabelecido por Baumel et al. (1993). De forma semelhante, Lane (2005) salientou que a distinção entre as vértebras cervicais, torácicas e lombares em crocodilianos não são claras e geram divergentes interpretações. Assim, a dificuldade de delimitação das regiões da coluna vertebral pode explicar, ao menos parcialmente, a variação no número de vértebras e costelas descritas na literatura.

A presença de duas VS em C. yacare, cada uma associada com um par de costelas sacrais, assemelha-se aos achados de Lima et al. (2011). No entanto, a variação das extremidades dos corpos vertebrais observada na região sacral de $C$. yacare pode ocorrer, segundo Hildebrand \& Goslow (2006), porque os corpos vertebrais dos répteis, geralmente procélicos, podem assumir outras formas, ocorrendo casos intermediários ou combinações diversas. Os presentes resultados em C. yacare assemelham-se à descrição das vértebras em Eusuchia, clado que inclui todos os atuais crocodiliformes, que possuem nove vértebras cervicais, 15 vértebras no tronco (VT e VL), duas vértebras sacrais e pelo menos 28 vértebras caudais. Todas, exceto as sacrais, são procélicas, cujo grau diminuiu em sentido caudal, o que é típico em Eusuchia. A aquisição de vértebras procélicas permitiu aos 
membros desse clado se tornarem nadadores eficientes, sem perder a capacidade do "andar alto" em terra (Salisbury et al. 2006).

Nove pares de costelas torácicas foram observados em C. Yacare, embora Lane (2005) tenha considerado oito pares de costelas "verdadeiras" em crocodilianos. Para Hildebrand \& Goslow (2006), as costelas originalmente estendiam-se ao longo de todo o comprimento da coluna vertebral para aumentar o contato direto dos músculos axiais com o esqueleto. Na medida em que aumentaram em comprimento, passaram a proteger as vísceras adjacentes. Em C. yacare, as costelas estão presentes ao longo da coluna vertebral, exceto nas duas últimas vértebras lombares e na região caudal. Para Schwarz-Wings (2009), as vértebras lombares (VL) mais caudais em Crocodylia perderam suas costelas no processo evolutivo.

Os processos uncinados que emergem da margem lateral do corpo das costelas torácicas em C. yacare já estavam presentes nos primeiros tetrápodes (Perry et al. 2010) e são encontrados na maioria das aves atuais, em dinossauros não aviários, em crocodilos e tuataras (Codd et al. 2008).

A disposição diferenciada das articulações entre as duas primeiras VT com as respectivas costelas, em relação às demais VT, observada em C. yacare, também foi descrito em $A$. mississippiensis (Reese 2000).

\section{Bases musculares do filé de lombo}

A divisão do m. semiespinhal em subunidades observada em crocodilianos também está presente em aves, sugerindo ser uma condição sinapomórfica para Archosauria (Organ 2006). Ainda, a distância percorrida pelos tendões do m. articuloespinhal em C. yacare segue o esperado nos atuais crocodilianos que, segundo Organ (2006) e Schwarz-Wings (2009), é de quatro a cinco segmentos vertebrais.

A presença de cones de miosseptos sucessivamente imbricados uns aos outros descritos no m. tendinoarticular de C. yacare assemelha-se ao observado em A. mississippiensis (Organ 2006). Já Schwarz-Wings (2009) considera o grupo do m. transverso espinhal em crocodilianos composto por quatro subunidades, compreendendo, no sentido medial para lateral, os músculos multífidos, espinhal, articuloespinhal e tendinoarticular, sendo que as três primeiras subunidades são separadas da última por um distinto septo. Esse septo também foi observado em $C$. yacare, entre as duas partes do m. semiespinhal (articuloespinhal e tendinoarticular).

A presença de cones de miossepto observados em $C$. yacare no m. longuíssimo dorsal corresponde ao já descrito em arcossáurios por Organ (2006), em crocodilianos e lepidosauros (Tsuihiji 2007). A ancoragem do m. longuíssimo dorsal, medialmente e lateralmente, por meio de sua fáscia superficial, respectivamente, no septo intermuscular dorsal e no septo transverso, é semelhante ao descrito em outros crocodilianos por Schwarz-Wings (2009) e Tsuihiji (2007). Os autores acrescentaram que aberturas na parte ventral do septo delimitador entre o $\mathrm{m}$. tendinoarticular e $\mathrm{m}$. longuíssimo dorsal permitem o entrelaçamento de suas fibras musculares. Para Schwarz-Wings (2009), esse mús- culo em crocodilianos ocupa o terço medial dos processos transversos, ao passo que em C. yacare se apoia sobre a parte mais lateral dos processos transversos das vértebras torácicas e lombares, enquanto na região sacral se apoia nas costelas sacrais. Para Organ (2006), os músculos epaxiais dentro do Crocodylia são os menos diversificados em relação aos outros grupos de répteis.

Também a morfologia do m. iliocostal dorsal observada em C. yacare é basicamente a mesma entre lepidosauros e crocodilianos, consistindo de tendões segmentares fixados nas costelas com fibras musculares conectadas entre eles (Tsuihiji 2007).

\section{Bases ósseas do corte Aparas}

A presença da gastrália em C. yacare pode ser considerada plesiomórfica para os tetrápodes, mas retida apenas em crocodilianos atuais e no tuatara (Sphenodon) onde é articulada, ou como parte do plastrão de quelônios, onde é imóvel (Claessens 2004, Vickaryous \& Hall 2008). 0 termo "gastrália" em substituição a "costelas abdominais" (Reese 2000) foi utilizado para designar as ossificações dérmicas situadas na parede abdominal ventral, anexada ao púbis e ao esterno por ligamentos e incorporadas nas camadas superficiais do músculo reto abdominal. A variação no número de linhas gastraliais observada em C. yacare, também foi referida em Alligator mississippiensis. Há ainda variabilidade no número de elementos presentes em cada linha, podendo ocorrer fusão, distribuição assimétrica ou ausência dos elementos (Claessens 2004, Vickaryous \& Hall 2008).

0 esterno tem as funções de reforçar a parede do corpo, proteger as vísceras torácicas e acomodar músculos dos membros torácicos, sendo cartilaginoso e grande em crocodilianos, conforme previamente descrito (Hildebrand \& Goslow 2006) e também observado no jacaré-do-Pantanal.

\section{Bases musculares do corte Aparas}

Nesta pesquisa, utilizaram-se as designações "serrátil superficial e profundo", por melhor expressar a disposição anatômica dessa musculatura em C. yacare. Esses termos também foram utilizados em lepidosauros, crocodilianos e aves (Dilkes 2000), além de A. mississippiensis (Tsuihiji 2007), muito embora nessa última espécie Wilhite (2003) tenha utilizado a denominação anterior e posterior. Por outro lado, Meers (2003) usou a denominação serrátil ventral cervical e torácico para crocodilianos (A. mississippiensis, Crocodylus siamensis, Crocodylus acutus, Osteolaemus tetraspis e Gavialis gangeticus), condição que não corresponde aos achados em C. yacare. Embora tenha ocorrido o rompimento da fixação do m. grande dorsal no tronco em função da esfola, foi observado em C. yacare, assim como registrado por Meers (2003) em outros crocodilianos, que a origem do músculo se dá na fáscia toracodorsal, cranialmente ao processo espinhoso da primeira vértebra torácica, estendendo-se linearmente até o nível da sexta costela torácica. Aliado a isso, aquele autor o considera um músculo anatomicamente conservado, por não ter apresentado variação.

Meers (2003) descreveu o m. peitoral em crocodilianos como variavelmente constituído por duas (cranial e 
caudal) ou três (cranial, caudal e profunda) cabeças, com a ocorrência da cabeça profunda somente em poucos espécimes de A. mississippiensis dissecados. Desta forma, o autor considerou o aparecimento dessa terceira cabeça uma variação intraespecífica. Na mesma espécie, Wilhite (2003) o descreveu como constituído por duas cabeças (anterior e posterior). Já nas dissecações em C. yacare, foram identificadas duas partes do m. peitoral, para as quais se preferiu utilizar os termos superficial e profundo devido à sua disposição anatômica.

A composição da musculatura abdominal em C. yacare assemelha-se a musculatura hipaxial na salamandra $\mathrm{Di}$ camptodon ensatus descrita por Carrier (1993) Porém, na salamandra Taricha torosa, Walthall \& Ashley-Ross (2006) identificaram somente uma camada no m. oblíquo abdominal externo. Embora haja variação no número de camadas presentes nessa musculatura em salamandras (Brainerd \& Simons 2000), o arranjo da parede latero-ventral da região abdominal dos tetrápodes é altamente conservador (Bhullar 2009).

A disposição do m. oblíquo abdominal externo em duas camadas foi descrita na salamandra $D$. ensatus (Carrier 1993) e identificada em outras salamandras por Brainerd \& Simons (2000) aonde quatro camadas de músculos hipaxiais laterais estavam presentes, com diferentes ângulos das fibras musculares em cada uma delas.

Os achados observados no m. oblíquo abdominal interno em $C$. yacare corroboram as informações apresentadas por Reese (2000) em Alligator mississippiensis. Por sua vez, as descrições relativas ao m. transverso abdominal assemelham-se à descrição existente para Alligator mississippiensis (Farmer \& Carrier 2000, Reese 2000); todavia, diferem quanto à fixação dorsal, que segundo Farmer \& Carrier (2000), se dá na porção proximal da "costela dorsal". Essa estrutura foi nominada nesta pesquisa como osso costal, onde o músculo iliocostal se localiza e cuja fáscia profunda serve de inserção para os músculos oblíquo abdominal externo profundo, oblíquo abdominal interno e transverso abdominal.

A disposição do m. reto abdominal em C. yacare não corresponde aos achados em iguana (Bhullar 2009). Nesta, foi identificado um músculo estreito, não segmentado, que reveste parcialmente as margens laterais do $\mathrm{m}$. reto abdominal, sendo o músculo mais superficial do tronco e denominado m.reto abdominal lateral. A forma do músculo registrada no jacaré-do-Pantanal também difere do que foi descrito em lagartos Autarchoglossa (Camp 1923), no qual é dividido em quatro partes (profundo, mediano, lateral e interno). No entanto, a descrição do m. reto abdominal em C. yacare assemelha-se aquela registrada em A. mississippiensis (Farmer \& Carrier 2000); porém, esses autores não fazem menção à divisão que a aponeurose dos músculos oblíquo abdominal interno e transverso abdominal fazem no músculo reto abdominal.

\section{Bases ósseas do filé mignon}

A descrição da pelve em $C$. yacare segue o raciocínio de Reese (2000) e se opõe à descrição de Lima (2010) na mesma espécie, na qual o púbis é referido exclusivamente como o componente extra-acetábulo. No entanto, para Rasskin-Gutman \& Buscalioni (2001), embora primitivamente os três elementos da pelve (ílio, ísquio e púbis) participassem da formação do acetábulo, há diferentes interpretações sobre a posição do púbis. Os autores consideraram o púbis uma estrutura altamente variável, constituída em crocodilianos por dois elementos, a parte acetabular (cartilaginosa), que conecta com a pelve, e a extra-acetabular (óssea). Tal descrição corrobora os resultados observados nesta pesquisa em C. yacare. Já Carrier \& Farmer (2000) consideraram os crocodilianos como únicos entre os tetrápodes existentes que possuem ossos púbicos excluídos do acetábulo e, por isso, possuem um sistema musculoesquelético pélvico altamente derivado; tal condição, para Naish (2001), parece ter ocorrido primeiramente no clado Mesoeucrocodylia, o grupo que inclui todos os modernos crocodilianos.

\section{Bases musculares do filé mignon}

A Nomina Anatomica Veterinaria (ICVGAN, 2012) preconiza a utilização dos termos "interno e externo" na musculatura dos membros somente para os músculos obturatórios, que estão localizados dentro e fora do forame obturatório. Assim, na designação do músculo puboisquiofemoral interno, o termo interno foi mantido devido à sua origem e a maior parte do trajeto ocorrer dentro da cavidade abdominal. Por sua vez, a designação de suas porções, 1 e 2, foram substituídas pelos termos caudal e cranial, respectivamente, devido a relação de sintopia de suas origens.

Dilkes (2000) descreveu a fixação do músculo m. puboisquiofemoral interno cranial em crocodilianos na superfície ventral e lateral do corpo e na superfície ventral dos processos transversos das VL se inserindo no fêmur. Essa descrição assemelha-se ao verificado nesta pesquisa no jacaré-do-Pantanal. Para Schachner et al. (2011), o m. puboisquiofemoral interno apresenta diferentes divisões em todos os sáurios existentes, sendo que os crocodilianos e a maioria dos lepidosauros têm dois componentes, ao passo que as aves e alguns esquamatas possuem três. Essa afirmação está de acordo com o descrito neste trabalho em C. yacare. Assim, a denominação desse músculo varia de acordo com a grupo taxonômico que está sendo descrito.

A extensão do m. troncocaudal em C. yacare, da extremidade lateral do segundo segmento lateral da gastrália até a margem caudo-lateral da cloaca, difere da descrição de Farmer \& Carrier (2000) em A. Mississippiensis, no qual este músculo insere-se nas margens laterais das quatro últimas gastralium e na fáscia do músculo reto abdominal e do músculo oblíquo abdominal externo.

\section{CONCLUSÕES}

Mediante os resultados encontrados nesta pesquisa, conclui-se que o corte filé de lombo em Caiman yacare é constituído pelos músculos semiespinhal, longuíssimo e iliocostal, e tem como base óssea as vértebras e costelas torácicas, lombares e sacrais.

O corte aparas em C. yacare é composto pelos músculos grande dorsal, serrátil, peitoral (superficial e profundo) e os abdominais (oblíquo externo, oblíquo interno, transverso e reto), cujas bases ósseas são as costelas torácicas, lom- 
bares, sacrais, a gastrália, o esterno e o epipúbis.

0 filé mignon em C. yacare é formado pelos músculos puboisquiofemoral interno cranial e troncocaudal, tendo como base óssea a gastrália, vértebras lombares, coxal e o fêmur.

Nesta região os músculos segmentados são: músculos semiespinhal, longuíssimo e iliocostal e a parte superficial do reto abdominal.

Agradecimentos.- À Coordenação de Aperfeiçoamento de Pessoal de Nível Superior (CAPES), pelo apoio financeiro, à Cooperativa dos Criadores de jacaré-do-Pantanal (Coocrijapan) pela doação dos exemplares utilizados no estudo e ao fotógrafo Lucas Ninno, sem o qual não conseguiria compartilhar a riqueza dos detalhes anatômicos do jacaré-do-Pantanal.

\section{REFERÊNCIAS}

Baumel J.J., King A.S., Breazile J.E., Evans H.E. \& Vanden Berge J.C. 1993. Handbook of Avian Anatomy: Nomina Anatomica Avium. $2^{\text {nd }}$ ed. Nuttall Ornithological Club, Cambridge. 779p.

Bhullar B.S. 2009. A reevaluation of the unusual abdominal musculature of squamate reptiles (Reptilia: Squamata). Anat. Rec. 292:11541161.

Brainerd E.L. \& Simons R.S. 2000. Morphology and function of lateral hypaxial musculature in salamanders. Am. Zool. 40:77- 86.

Camp C.L. 1923. Classification of the lizards. [on line]. Bull. Am. Mus. Nat. Hist., New York. Disponível em <http://hdl.handle.net/2246/898> Acesso em 3 dez. 2012.

Carrier D.R. 1993. Action of the hypaxial muscles during walking and swimming in the salamander Dicamptodon ensatus. J. Exp. Biol. 180:75-83.

Carrier D.R. \& Farmer C.G. 2000. The integration of ventilation and locomotion in archosaurs. Am. Zool. 40:87-100.

Claessens L.P.A.M. 2004. Dinosaur gastralia: origin, morphology, and function. J. Vertebr. Paleontol. 24:89-106.

Codd J.R., Manning P.L., Norell M.A. \& Perry S.F. 2008. Avian-like breathing mechanics in maniraptoran dinosaurs. Proc. R. Soc. Lond. B, Biol. Sci. [on line] 275:157-161, Disponível em <rspb.royalsocietypublishing.org> Acesso em 28 jul. 2012.

Cossu M.E., González O.M., Wawrzkiewicz M., Moreno D. \& Vieites C.M. 2007. Carcass and meat characterization of "yacare overo" (Caiman latirostris) and "yacare negro" (Caiman yacare). Braz. J. Vet. Res. Anim. Sci. 44(5):329-336.

Dilkes D.W. 2000. Appendicular myology of the hadrosaurian dinosaur Maiasaura peeblesorum from the Late Cretaceous (Campanian) of Montana. Trans. R. Soc. Edinb. Earth Sci. 90(2):87-125.

Farmer C.G. \& Carrier D.R. 2000. Pelvic aspiration in the American alligator (Alligator mississippiensis). J. Exp. Biol. 203:1679-1687.

Girardi W.C., Da Silva J.A. \& Toral F.L.B. 2008. Efeito do peso ao abate do jacaré-do-Pantanal (Caiman yacare, Daudin 1802) sobre rendimentos de cortes comerciais da carcaça. Anais 45 a Reunião Anual da Sociedade Brasileira de Zootecnia, Lavras, MG.

Hildebrand M. \& Goslow J.R.G.E. 2006. Esqueleto do corpo, p.141-167. In: Ibid. (Eds), Análise da Estrutura dos Vertebrados. 2 ${ }^{\mathrm{a}}$ ed. Editora Atheneu, São Paulo. 638p.

International Committee on Veterinary Gross Anatomical Nomenclature. Nomina Anatomica Veterinaria 2012. [online]. $5^{\text {th }}$ ed. Editorial Committee, Hannover. Disponível em <http://www.wava-amav.org/Downloads/nav_2012.pdf> Acesso em 26 abr. 2013.

Lane T.J. 2005. Crocodilians, p.78-94. In: Mader D.R. (Ed.), Reptile Medicine and Surgery. W.B. Saunders, Philadelphia. 1242p.

Lima F.C. 2010. Desenvolvimento do esqueleto em embriões de Caiman yacare (Daudin, 1802) (Crocodylia, Alligatoridae). Dissertação de Mestrado em Ciências Veterinárias, Universidade Federal de Uberlândia, Uberlândia, MG. 123p.
Lima F.C., Vieira L.G., Santos A.L.Q., Pereira H.C., Alves P.H.M. \& Assumpção T.I. 2011. Esqueletogênese dos ossos da coluna vertebral, costelas e esqueleto abdominal em embriões de Caiman yacare (Crocodylia: Alligatoridae). Biosci. J. 27(5):813-825.

Meers M.B. 2003. Crocodylian forelimb musculature and its relevance to archosauria. Anat. Rec. A 27(4A):891- 916.

Naish D. 2001. Crocodilians. Geol. Today 17(2):71-77.

Organ C.L. 2006. Biomechanics of ossified tendons in ornithopod dinosaurs. Paleobiol. 32(4):652-665.

Otero A., Gallina P.A. \& Herrera Y. 2010. Pelvic musculature and function of Caiman latirostris. J. Herpetol. 20:173-184.

Perry S.F., Similowski T., Klein W. \& Codd J.R. 2010. The evolutionary origin of the mammalian diaphragm. Respir. Physiol. Neurobiol. 171(1):1-16.

Rasskin-Gutman D. \& Buscalioni A.D. 2001. Theoretical morphology of the Archosaur (Reptilia: Diapsida) pelvic girdle. Paleobiol. 27(1):59-78.

Reese A.M. 2000. The alligator and its allies. [online]. Arment Biological, Landisville. Disponível em <www.herper.com/ebooks> Acesso em 20 ago. 2009.

Rodrigues E.C., Bressan M.C., Vicente Neto J., Oliveira e Vieira J., Farias P.B., Ferrão S.P.B. \& Andrade P.L. 2007. Qualidade e composição química de cortes comerciais de carne de jacaré-do-Pantanal (Caiman yacare). Ciênc. Agrotec. 31(2):448-455

Salisbury S.W., Molnar R.E., Frey E. \& Willis P.M.A. 2006. The origin of modern crocodyliforms: new evidence from the Cretaceous of Australia. Proc. R. Soc. Lond. Biol. Sci. [on line] 273:2439-2448. Disponível em <rspb.royalsocietypublishing.org> Acesso em 6 mai. 2013.

Schachner E. R., Manning P.L. \& Dodson P. 2011. Pelvic and hindlimb myology of the basal Archosaur Poposaurus gracilis (Archosauria: Poposauroidea). J. Morph. 272:1464-1491.

Schwarz-Wings D. 2009. Reconstruction of the thoracic epaxial musculature of Diplodocid and Dicraeosaurid Sauropods. J. Vertebr. Paleontol. 29(2):517- 534

Silva E.M., Dias G., Tavares M., Marques T. \& Furtado J.M. 2008. Estudo analítico da Técnica de Glicerinação empregada para conservação de peças anatômicas - experiência da disciplina de Anatomia Humana do Departamento de Morfologia do UniFOA. Cadernos UniFOA 3.

Superintendência Federal da Agricultura, Pecuária e Abastecimento no Estado de Mato Grosso - SFA/MT. 2013. Dados sobre a produção de cortes de jacaré em entrepostos de pescado sob SIF - Serviço de Inspeção Federal. Mensagem recebida por Figueiredo S.I.S. (sandrafigueiredo@ ufmt.br). Acesso em 27 mar. 2013.

Tsuihiji T. 2007. Homologies of the longissimus, iliocostalis, and hypaxial muscles in the anterior presacral region of extant diapsida. J. Morph. 268:986-1020.

Vicente Neto J., Bressan M.C., Faria P.B., Vieira J.O., Cardoso M.G., Glória M.B.A. \& Gama L.T. 2010. Fatty acid profiles in meat from Caiman yacare (Caiman crocodilus yacare) raised in the wild or in captivity. Meat Sci. 85:752-758

Vickaryous M.K. \& Hall B.K. 2008. Development of the dermal skeleton in Alligator mississippiensis (Archosauria, Crocodylia) with comments on the homology of osteoderms. J. Morph. 269:398-422.

Vieira J.P., Da Silva T.J.P., Freitas M.Q., Fontenelle G., Lindote H.C.F. \& Freitas M.A.M. 2012. Caracterização do processo de rigor mortis do músculo Ilio-ischiocaudalis de jacaré-do-Pantanal (Caiman crocodilus yacare) e maciez da carne. Ciência Rural 42(3):567-572.

Vieira L.G., Lima F.C., Santos A.L.Q., Mendonça S.H.S.T., Moura L.R., Iasbeck J.R. \& Sebben A. 2011. Description of embryonic stages in Melanosuchus niger (Spix, 1825) (Crocodylia: Alligatoridae). Braz. J. Morphol. Sci. 28(1):11-22.

Walthall J.C. \& Ashley-Ross M.A. 2006. Postcranial myology of the California Newt, Taricha torosa. Anat. Rec. A 288:46-57.

Wilhite R. 2003. Biomechanical reconstruction of the appendicular skeleton in three North American jurassic sauropods. PhD Dissertation, Department of Geology and Geophysics, Louisiana State University and Agricultural and Mechanical College, Louisiana. 231p. 